See Article page 1 in the September 2020 issue.

\section{Commentary: A nano-sized step for man, a giant step for mankind?}

\author{
Adam R. Williams, MD, ${ }^{\mathrm{a}}$ and Edward P. Chen, $\mathrm{MD}^{\mathrm{b}}$
}

Naganuma and colleagues ${ }^{1}$ present a unique and novel technique to mitigate spinal cord injury (SPI) using nanobubble technology to oxygenate cerebrospinal fluid (CSF), administered via intrathecal microcatheter infusion. Using a validated rabbit model of SCI involving 15 minutes of infrarenal aorta occlusion, animals were assigned to 1 of 4 groups: (1) sham procedure group $(n=5)$, with microcatheter placement and 5 seconds of aortic occlusion; (2) ischemia only group $(n=5)$, with microcatheter placement and 15 minutes of aortic occlusion; (3) nonoxygenated ischemia group ( $\mathrm{n}=5)$, with 15 minutes of aortic occlusion followed by microcatheter infusion of nonoxygenated CSF; and (4) oxygenated ischemia group $(n=5)$, with 15 minutes of aortic occlusion followed by microcatheter infusion of oxygenated CSF. Artificial CSF infusion was initiated 15 minutes after aortic occlusion and lasted 60 minutes. Partial pressure of oxygen in CSF $\left(\mathrm{CSF}-\mathrm{PO}_{2}\right)$ was assessed during the procedure. At 48 hours, a neurologic evaluation was performed for hind limb function, and the animals were euthanized for histological spinal cord analysis by a blinded pathologist.

The authors report that after ischemia-reperfusion injury, oxygenated artificial CSF generated higher CSF- $\mathrm{PO}_{2}$ and improved neurologic function compared with ischemia alone or unoxygenated artificial CSF. Furthermore, oxygenated CSF infusion downregulated expression of neuronal inflammatory cytokines IL-6, TNF, and IL-1. The authors should be complimented for this innovative strategy of applying nanotechnology to generate oxygenated CSF that improves neurologic function after SPI and elucidating

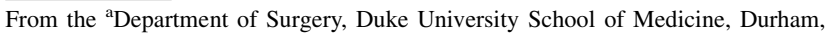
NC; and ${ }^{\mathrm{b}}$ Department of Surgery, Emory University School of Medicine, Atlanta, $\mathrm{Ga}$.

Disclosures: The authors reported no conflicts of interest.

The Journal policy requires editors and reviewers to disclose conflicts of interest and to decline handling or reviewing manuscripts for which they may have a conflict of interest. The editors and reviewers of this article have no conflicts of interest.

Received for publication Sept 24, 2020; revisions received Sept 24, 2020; accepted for publication Sept 25, 2020; available ahead of print Oct 29, 2020.

Address for reprints: Edward P. Chen, MD, Department of Surgery, Emory University School of Medicine, 5665 Peachtree Dunwoody Rd, Suite 200, Atlanta, GA 30342 (E-mail: edward.p.chen@emory.edu).

JTCVS Open 2021;5:37-8

2666-2736

Copyright (C) 2020 The Authors. Published by Elsevier Inc. on behalf of The American Association for Thoracic Surgery. This is an open access article under the CC BY-NCND license (http://creativecommons.org/licenses/by-nc-nd/4.0/).

https://doi.org/10.1016/j.xjon.2020.09.007
}

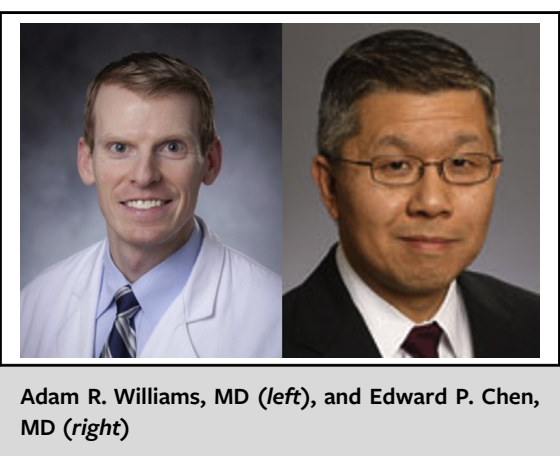

CENTRAL MESSAGE

Nanobubble-oxygenated artificial cerebrospinal fluid reduces inflammation and improves neurologic function in a rabbit model of spinal cord injury.

a potential mechanism of action via decreasing spinal cord inflammation.

SCI remains a devastating complication of surgical intervention for distal aortic pathology. Various perioperative and intraoperative interventions have been described as protective measures to decrease the incidence of SCI; these include the use of CSF drainage and permissive hypertension, ${ }^{2}$ systemic hypothermia with distal aortic perfusion using left heart bypass or partial cardiopulmonary bypass, ${ }^{3}$ and reimplantation of large segmental blood vessels (intercostal and lumbar arteries). Preservation of nonsegmental blood vessels (subclavian and hypogastric arteries) is being increasingly recognized as critical to maintaining spinal cord circulation during endovascular aortic repair. ${ }^{4}$ In addition, the development of a collateral network of spinal cord circulation (via staged procedures or preliminary occlusion of segmental arteries before repair) has emerged as an important concept to mitigate SCI. ${ }^{5}$ Despite these advancements, however, paraplegia rates continue to range from roughly $2 \%$ to $13 \%$, and more innovative therapies are needed to prevent these catastrophic complications.

Two important questions remain regarding the safety of spinal canal irrigation with artificial CSF and the potential for increasing intrathecal pressure. Introducing a foreign substance into the spinal canal during an already vulnerable ischemic state is suboptimal owing to the risk of infection, and additional studies are needed before clinical application. Artificial CSF infusion into the spinal canal will inevitably increase spinal cord pressure and ischemia, requiring more innate CSF drainage to allow for infusion of the 
artificial CSF. The safety profile of oxygenated artificial CSF also merits further investigation.

We congratulate the authors on this well-designed study and look forward to future studies applying nanobubble technology for the treatment of SCI.

\section{References}

1. Naganuma M, Saiki Y, Kanda K, Akiyama M, Adachi O, Horii A, et al. Nanobubble technology to treat spinal cord ischemic injury. J Thorac Cardiovasc Surg Open. 2020;3:1-11.
2. Coselli JS, LeMaire SA, Koksoy C, Schmitling ZC, Curling PE. Cerebrospinal fluid drainage reduces paraplegia after thoracoabdominal aortic aneurysm repair: results of a randomized clinical trial. J Vasc Surg. 2002;35:631-9.

3. Estera AL, Miller CC, Chen EP, Meada R, Torres RH, Porat EE, et al. Descending thoracic aortic aneurysm repair: 12 year experience using distal aortic perfusion and cerebrospinal fluid drainage. Ann Thorac Surg. 2005;80:1290-6.

4. Eagleton MJ, Shah S, Petkosevek D, Mastracci TM, Greenberg RK. Hypogastric and subclavian artery patency affects onset and recovery of spinal cord ischemia associated with aortic endografting. J Vasc Surg. 2014;59:89-95.

5. Griepp RB, Griepp EB. Spinal cord protection in surgical and endovascular repair of thoracoabdominal aortic disease. J Thorac Cardiovasc Surg. 2015; 149(suppl):S86-90. 